\title{
PENGENDALIAN PLUTELLA XYLOSTELLA DENGAN METARHIZIUM ANISOPLIAE DALAM MENGURANGI INTENSITAS KERUSAKAN DAN MEMPERTAHANKAN HASIL KUBIS
}

\section{CONTROL OF PLUTELLAXYLOSTELLA WITH METARHIZIUM ANISOPLIAE IN REDUCING DAMAGE INTENSITY AND MAINTAINING CABBAGE RESULTS}

\author{
Dina Gustiana ${ }^{*}$, Cecep Hidayat ${ }^{2} \&$ Yati Setiati $^{3}$ \\ 1,2,3Jurusan Agroteknologi, UIN Sunan Gunung Djati Bandung \\ *Korespondensi : dinagustiana95@gmail.com
}

\begin{abstract}
ABSTRAK
Tingkat serangan P. xylostella sangat berpengaruh terhadap produksi tanaman kubis. Tujuan penelitian ini adalah untuk mengendalikan P. xylostella dengan M. anisopliae dalam mengurangi Intensitas Kerusakan dan mempertahankan hasil Kubis. Penelitian ini dilaksanakan di Laboratorium jurusan Agroteknologi, Fakultas Sains dan Teknologi Universitas Islam Negeri Sunan Gunung Djati Bandung dan di Desa Sukarapih, Kecamatan Sukasari, Kabupaten Sumedang dari bulan Januari sampai bulan mei 2017. Metode yang digunakan adalah metode eksperimental berupa Rancangan Acak Lengkap (RAL) sederhana dengan faktor kerapatan spora M. anisopliae. Penelitian terdiri dari kontrol negatif, kontrol positif, $10^{5}, 10^{6}, 10^{7}, 10^{8}, 10^{9}$, dan $10^{10} \mathrm{ml}^{-1}$ aquades sehingga terdapat 8 perlakuan yang diulang 3 kali. Uji lanjut yang digunakan adalah Uji Jarak Berganda Duncan (UJBD) taraf 5\%. Pengujian dilakukan pada larva P. xylostella dengan cara menyem rotkan suspensi spora M. anisopliae pada tanaman kubis. Hasil penelitian menunjukkan bahwa kerapatan $10^{10}$ spora $\mathrm{ml}^{-1}$ memiliki peresentasi intensitas kerusakan sebes ar 3,12\% dimana hasil persentase intensitas kerusakan yang dihasilkan lebih rendah dibandingkan dengan perlakuan lainnya. Pada perlakuan kerapatan $10^{10} \mathrm{ml}^{-1}$ spora berpengaruh juga terhadap pertumbuhan diameter krop kubis dimana setiap minggunya meningkat, hal ini dapat dipengaruhi karena pada perlakuan $10^{10} \mathrm{ml}^{-1}$ spora intensitas kerusakan tanaman rendah sehingga berpengaruh terhadap pertumbuhan diam eter krop kubis dan menghasilkan bobot segar kubis dengan rata-rata sebesar $691,53 \mathrm{~g}_{\text {tanaman-1}}{ }^{-1}$. Semakin rendah intensitas serangan hama maka pertumbuhan diameter krop dan hasil tanaman kubis dapat dipertahankan.
\end{abstract}

Kata kunci : Pengendalian, P. xylostella, M. anisopliae, Pertumbuhan dan Hasil

\begin{abstract}
The attack level of $P$. xylostella is very influential on the production of cabbage plants. The purpose of this study was to control P. xylostella with M. anisopliae in reducing damage intensity and maintaining cabbage yield. This res earch was conducted at the Laboratory of Agrotechnology, Faculty of Science and Technology of the State Islamic University of Sunan Gunung Djati Bandung and in Sukarapih Village, Sukasari District, Sumedang Regency from January to May 2017. The method used was an experimental method in the form of Completely Randomized Design (CRD) simple with $M$. anisopliae spore density factor. The study consisted of negative controls, positive controls, $10^{5}, 10^{6}, 10^{7}, 10^{8}, 10^{9}$, and $10^{10} \mathrm{ml}-1$ aquades so that there were 8 treatments repeated 3 times. The further test used was Duncan's Multiple Distance Test (UJBD) level of 5\%. Tests were performed on P. xylostella larvae by spraying the suspension of M. anisopliae spores on cabbage plants. The results showed that the density of $10^{10} \mathrm{ml}$ of 1 -spore had a percentage of damage intensity of $3.12 \%$ where the results of the percentage of intensity of damage produced were lower compared to other treatments. In the density treatment of $10^{10} \mathrm{ml}-1$ spores also affects the growth of cabbage crop diameter where each week increases, this can be affected because in the treatment of $10^{10} \mathrm{ml}-1$ spore the intensity of crop damage is low so that it affects the growth of cabb age crop diameter and produces a fresh weight of cabbage ev enly average of $691.53 \mathrm{~g}$ of plant-1. The lower
\end{abstract}


the intensity of pest attacks, the growth of crop diameter and yield of cabbage plants can be maintained.

Keywords: Control, P. xylostella, M. anisopliae, Growth and Results

\section{PENDAHULUAN}

Serangan larva Plu tella xylostella (L.) akan mengakibatkan daun tanaman berlubang dan tinggal tulang-tulang daun (Kalshoven, 1981).Salah satu kendala dalam budidaya tanaman kubis adalah serangan hama ini yang dapat menyebabkan kerusakan pada tanaman hingga berdampak pada penurunan tingkat produksi kubis. Hama kubis merusak tanaman pada stadium larva, dimana larva $P$. xylostella mulai menyerang tanaman kubis pada saat tanaman kubis memiliki 3 sampai 4 helai daun dan berlanjut hingga tanaman menjelang panen.

Pengendalian P. xylostella saat ini masih banyak menggunakan pestisida sintetik. Penggunaan pestisida sintetik tersebut dapat berpengaruh negatif pada produk pertanian. Salah satu alternatif pengendalian hama yang dapat mengurangi dampak negatif penggunaan pestisida sintetik ialah penggendalian hama secara hayati berupa cendawan entomopatogen yang bersifat patogen hanya pada serangga sasaran. Pengurangan penggunaan pestisida di areal pertanian menuntut tersedianya cara pengendalian lain yang aman dan ramah lingkungan, diantaranya dengan memanfaatkan agen hayati seperti entomopatogen (Trizelia et al., 2011). Cendawan entomopatogen yang sangat potensial dalam mengendalikan hama $P$. xylostella adalah M. anisopliae. Cendawan $M$. anisopliae dapat menyebabkan penyakit "green muscardin fungus" yang bersifat patogen terhadap serangga sasaran. $M$. anisopliae menghasilkan endotoksin yaitu Destruxins dimana senyawa ini dapat menyebabkan kelumpuhan dan kematian pada serangga. Efek destruxin berpengaruh pada organella sel target (mitokondria, retikulum endoplasma dan membrane nukleus), menyebabkan paralisa sel dan kelainan fungsi lambung tengah, tubulus malphigi, hemocyt dan jaringan otot (Widiyanti dan Muyadihardja, 2004).

Beberapa hasil penelitian menunjukkan bahwa $M$. anisopliae efektif dalam mengendalikan populasi serangga dari ordo Lepidoptera. Larva Maruca vitrata instar 3 yang di infeksikan cendawan $M$. anisopliae dengan kerapatan $2 \times 10^{6}$ spora ml1 dapat menyebabkan mortalitas larva hingga 49\% pada 6 hari setelah aplikasi (Toffa Mehinto, 2014).

Penelitian ini bertujuan untuk mengendalikan $P$. xylostella dengan $M$. anisopliae dalam Mempertahankan Intensitas Kerusakan dan Hasil Tanaman Kubis.

\section{BAHAN DAN METODE PENELITIAN}

Penelitian ini dilaksanakan di Laboratorium Hama jurusan Agroteknologi, Fakultas Sains dan Teknologi Universitas Islam Negeri Sunan Gunung Djati Bandung dan di Desa Sukarapih, Kecamatan Sukasari, Kabupaten Sumedang dari bulan Januari sampai bulan mei 2017. Bahan yang 
digunakan diantaranya isolat M. anisopliae, larva P. xylostella, Aquades dan tanaman kubis. Alat yang digunakan diantaranya semprotan. Metode yang digunakan adalah metode eksperimental berupa Rancangan Acak Lengkap (RAL) sederhana dengan perlakuan diantaranya kontrol positif, Kontrol negatif, kerapatan spora $M$. anisopliae $10^{5}, 10^{6}, 10^{7}, 10^{8}, 10^{9}$ dan $10^{10} \mathrm{ml}^{-1}$ aquades sehingga terdapat 8 perlakuan yang diulang sebanyak 3 kali sehingga diperoleh 24 unit percobaan.

\section{Pelaksanaan Penelitian persiapan} penelitian dengan menyediakan bahan dan alat yang dibutuhkan selama pelaksanaan penelitian. Tahap pertama melakukan pemeliharaan dan perbanyakan P. xylostella 2. Isolat cendawan $M$. anisopliae diperoleh dari BALITSA (Balai Penelitian Tanaman Sayuran) Lembang, Kabupaten Bandung Barat. Isolat M. anisopliae tersebut hasil isolasi P. xylostella dari tanaman bunga kol, isolat M. anisopliae disubkultur pada media PDA dengan komposisi 1 l eks trak kentang, gula pasir $20 \mathrm{~g}$ dan $7 \mathrm{~g}$ agar-agar tidak berwarna dan diinkubasi pada suhu ruang selama 7 hari.

Aplikasi suspensi M. ansopliae dilakukan di laboratorium. Langkah pertama yang dilakukan yaitu membuat larutan suspensi cendawa $M$. anisopliae dengan kerapatan kontrol positif, Kontrol negatif (0 spora ml-1) , kerapatan spora M. anisopliae $10^{5}, 10^{6}, 10^{7}$, $10^{8}, 10^{9} \mathrm{dan} \quad 10^{10} \mathrm{ml}^{-1}$, masing-masing perlakuan diulang sebanyak tiga kali. Setelah membuat larutan suspensi, kemudian diaplikasikan pada larva P. xylostella instar 2 pada tanaman kubis sebanyak 10 ekor. Aplikasi M. anisopliae dilakukan dengan cara disemprotkan pada larva P. xylostella.

Rancangan respon yang diamati diantaranya; (a) Intensitas Kerusakan Tanaman (\%) Pengamatan dilakukan setelah aplikasi cendawan entomopatogen $M$. anisopliae yaitu pada 11 hari setelah aplikasi Berikut cara menghitung persentase intensitas serangan hama dengan menggunakan rumus (Norman et al., 1997) sebagai berikut :

$\mathrm{IK}=\sum((\mathrm{n} \times \mathrm{v})) /(\mathrm{Z} \times \mathrm{N}) \mathrm{X} 100 \%$

Keterangan :

IK : Intensitas kerusakan (\%)

n : Jumlah unit sampel dengan skor tertentu

v : Nilai skor dari setiap katagori serangan

$\mathrm{N} \quad$ : Jumlah seluruh unit sampel yang diamati

Z : Skor tertinggi yang digunakan

(b) Diameter krop tanaman kubis (cm) Diukur dengan menggunakan meteran kain dari bagian daun terluar tanaman. Pengukuran dilakukan pada 10 hari setelah aplikasi cendawan entomopatogen $M$. anisopliae dengan interval pengukuran satu minggu sekali hingga panen; (c) Bobot segar kubis (g) Pengamatan dilakukan setelah panen, dengan menimbang hasil bobot krop kubis untuk setiap unit percobaan.

\section{HASIL DAN PEMBAHASAN}


a) Intensitas Kerusakan Tanaman (\%)

Berdasarkan hasil analisis ragam menunjukkan bahwa pengaplikasian beberapa tingkat kerapatan spora $M$. anisopliae berpengaruh nyata terhadap intensitas kerusakan tanaman Tabel 1.

Tabel 1 Pengaruh kerapatan spora M. anisopliae terhadap Intensitas kerusakan tanaman pada umur 59 HST (\%)

\begin{tabular}{lc}
\hline Kerapatan M. anisopliae & Intenitas Kerusakan \\
$(\mathrm{spora} / \mathrm{ml})$ & Tanaman $(\%)$
\end{tabular}

\begin{tabular}{lr}
\hline$A=0$ Kontrol $(-)$ & $0,00 \mathrm{a}$ \\
$\mathrm{B}=0$ Kontrol $(+)$ & $15,87 \mathrm{~h}$ \\
$\mathrm{C}=10^{5}$ & $13,68 \mathrm{~g}$ \\
$\mathrm{D}=10^{6}$ & $12,06 \mathrm{f}$ \\
$\mathrm{E}=10^{7}$ & $9,91 \mathrm{e}$ \\
$\mathrm{F}=10^{8}$ & $6,58 \mathrm{~d}$ \\
$\mathrm{G}=10^{9}$ & $4,75 \mathrm{c}$ \\
$\mathrm{H}=10^{10}$ & $3,12 \mathrm{~b}$ \\
\hline
\end{tabular}

Keterangan : Angka-angka pada lajur yang diikuti oleh huruf yang sama tidak berbeda nyata menurut Uji jarak Berganda Duncan pada taraf $5 \%$

Intensitas kerusakan tanaman diamati pada saat pengujian utama telah selesai dilakukan yaitu pada saat tanaman memasuki umur 59 HST, dimana pada umur 48 HST tanaman kubis dilakukan investasi larva sebanyak 10 ekor per tanaman, kemudian diaplikasikan M. anisopliae dengan lama pengujian 10 hari setelah aplikasi. Berdasarkan hasil pengamatan Dari Tabel 1 beberapa tingkat kerapatan spora dapat berpengaruh nyata terhadap presentase intensitas kerusakan tanaman. Berdasarkan hasil pengujian yang dilakukan terdapat intensitas kerusakan tertinggi yang terjadi pada kontrol positif yaitu sebesar 15,87\%. Aktivitas makan larva tidak terhambat karena tidak diberi perlakuan aplikasi $M$. anisopliae sehingga tingkat serangan pada tanaman akan semakin tinggi. Berbeda dengan perlakuan kerapatan $10^{10}$ $\mathrm{ml}^{-1}$ spora aquades peresentasi intensitas kerusakan 3,12\% dan berbeda nyata dengan perlakuan lainnya.
Kerapatan mulai dari $10^{5} \mathrm{ml}^{-1}$ spora sampai dengan $10^{9} \mathrm{ml}^{-1}$ spora aquades persentase intensitas kerusakan yang dihasilkan lebih rendah dibandingkan dengan kontrol positif, sehingga penggunaan M. anisopliae efektif untuk menekan intensitas serangan larva P. xylostella. Semakin tinggi kerapatan spora yang diberikan maka akan semakin rendah intensitas serangannya.

Tanaman kubis yang terserang oleh larva P. xylostella dengan intensitas serangan tinggi mengakibatkan bagian permukaan daun berlubang (Gambar 1) dan hanya akan meninggalkan epidermis bagian atas daun bahkan hanya menyisakan tulang daun, apabila sampai ke titik tumbuh akan mengakibatkan pembentukan krop terhambat.

M. anisopliae sebagai agen hayati bersifat kontak sehingga larva yang menyerang tanaman kubis semakin lama aktivitas makannya akan semakin berkurang. 
Menurut Tanada dan Kaya (1993), spora cendawan yang melekat pada permukaan kutikula larva akan membentuk hifa dan memasuki jaringan internal larva melalui interaksi biokimia yang kompleks antara larva dan cendawan. Selanjutnya enzim yang dihasilkan oleh cendawan berfungsiuntuk mendegradasi kutikula larva, kemudian hifa cendawan akan tumbuh ke dalam sel-sel tubuh serangga dan menyerap cairan tubuh serangga. Oleh karena itu semua aktivitas makan dari larva akan terhambat.

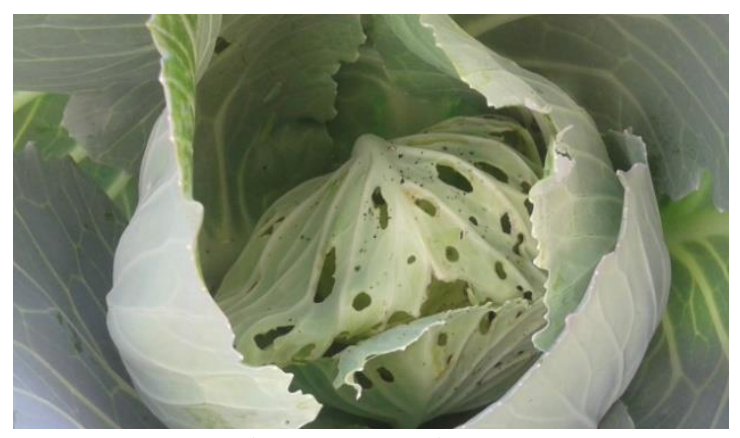

Gambar 1 Kerusakan Tanaman

Hasil dari penelitian yang telah dilakukan intensitas kerusakan tanaman kubis oleh larva $P$. xylostella tertinggi yaitu $15,87 \%$ masih berada di bawah ambang pengendalian. Walaupun intensitas serangan masih tergolong rendah, pengendalian OPT tetap harus dilakukan, hal ini merupakan salah satu upaya pencegahan yang dapat dilakukan untuk menekan intensitas serangan $\quad P$. xylostella. Dengan dikendalikannya serangan $P$. xylostella maka, pertumbuhan dan hasil tanaman dapat dipertahankan.

\section{b) Diameter krop kubis}

Pengukuran diameter krop dilakukan dari bagian tulang daun hingga daun terluar tanaman. Hasil analisis ragam menunjukkan bahwa perlakuan dari beberapa tingkat kerapatan spora berpengaruh nyata terhadap diameter krop dari minggu ke 1 sampai minggu ke 4 setelah aplikasi Tabel 2 .

Berdasarkan Tabel 2 rata-rata pertumbuhan diameter krop mengalami peningkatan disetiap minggunya, pertumbuhan krop tidak lepas dari faktor pemberian perlakuan kerapatan spora, tanaman kontrol negatif pertumbuhan tanaman normal tidak terjadi adanya serangan hama sedangkan tanaman dengan kontrol positif pertumbuhan tanaman terhambat, karena adanya serangan hama dan tidak diberikan perlakuan aplikasi M.anisopliae.

Larva memakan setiap bagian di permukaan daun sehingga daun kubis berlubang dan apabila sampai kepada titik tumbuh tanaman maka pertumbuhan krop kubis akan terhambat bahkan dapat menyebabkan krop kubis tidak akan terbentuk. Pada perlakuan kerapatan $10^{10} \mathrm{ml}^{-}$ 1 spora, untuk setiap minggunya pertumbuhan diameter krop kubis meningkat, hal ini dapat dipengaruhi karena pada perlakuan $10^{10} \mathrm{ml}^{-1}$ spora dapat menyebabkan mortalitas atau tingkat kematian larva P. xylostella sebesar 83,33\% (Tabel 2).

Serangan yang ditimbulkan larva $P$. xylostella pada daun tidak menghambat tanaman untuk melakukan proses fotosintesis karena serangan yang terjadi tidak seluruhnya merusak bagian daun tanaman. Oleh karena itu pemberian perlakuan $M$. anisopliae dengan kerapatan $10^{10} \mathrm{ml}^{-1}$ spora mampu mempertahankan pertumbuhan kubis. 
Tabel 2 Pengaruh kerapatan spora M. anisopliae terhadap Diameter Krop Kubis pada 1- 4 MSA

\begin{tabular}{|c|c|c|c|c|c|}
\hline \multirow[t]{2}{*}{$\begin{array}{l}\text { Kerapatan M.anisopliae } \\
\text { (spora } / \mathrm{ml} \text { ) }\end{array}$} & \multicolumn{5}{|c|}{$\begin{array}{c}\text { Diameter Krop Kubis (cm) } \\
\text { Mingu Setelah Aplikasi }\end{array}$} \\
\hline & 1 & 2 & 3 & & 4 \\
\hline$A=0$ Kontrol $(-)$ & $8,23 \mathrm{de}$ & $11,20 \mathrm{e}$ & $14,60 \mathrm{f}$ & 16,43 & $\mathrm{~g}$ \\
\hline $\mathrm{B}=0$ Kontrol $(+)$ & 4,93 a & 6,10 a & 7,93 a & 10,23 & $\mathrm{a}$ \\
\hline$C=10^{5}$ & $6,30 \mathrm{~b}$ & $8,03 \mathrm{~b}$ & $9,66 \mathrm{~b}$ & 12,43 & $\mathrm{~b}$ \\
\hline$D=10^{6}$ & 6,70 bc & 9,76 c & $11,90 \mathrm{c}$ & 13,53 & c \\
\hline$E=10^{7}$ & 8,23 de & $9,96 \mathrm{c}$ & $12,20 \mathrm{~cd}$ & 13,86 & $\mathrm{~cd}$ \\
\hline$F=10^{8}$ & 7,13 bc & $10,16 \mathrm{~cd}$ & $12,23 \mathrm{~cd}$ & 14,30 & $\mathrm{~d}$ \\
\hline $\mathrm{G}=10^{9}$ & 8,76 e & $10,53 \mathrm{~cd}$ & $13,03 \mathrm{e}$ & 14,70 & $\mathrm{e}$ \\
\hline $\mathrm{H}=1010$ & $7,83 \mathrm{~cd}$ & $11,03 \mathrm{e}$ & $13,03 \mathrm{e}$ & 15,43 & $\mathrm{f}$ \\
\hline
\end{tabular}

Keterangan : Angka-angka pada lajur yang diikuti oleh huruf yang sama tidak berbeda nyata menurut Uji jarak Berganda Duncan pada taraf 5\%

\section{c) Hasil Bobot Segar Kubis}

Menurut Harjadi (1986) berat segar krop kubis adalah pertambahan ukuran dan kepadatan kropkubis yang telah dipanen kemudian ditimbang untuk mendapatkan nilai bobot segar kubis. Hasil analisis statistik menunjukkan bahwa pengaruh pemberian tingkat kerapatan spora $M$. anisopliae yang berbeda nyata terhadap bobot segar kubis dapat dilihat pada Tabel 3.

Berdasarkan penelitian pada perlakuan kontrol positif, menghasilkan rata-rata bobot segar sebesar $308 \mathrm{~g}_{\text {tanaman-1. Perlakuan }}$ pada tingkat kerapatan $10^{10} \mathrm{ml}^{-1}$ spora dapat

Tabel 3 Pengaruh Kerapatan Spora M. anisopliae terhadap Bobot Segar Kubis (g)

\begin{tabular}{lc}
\hline Kerapatan M. anisopliae spora/ ml & Bobot Segar Kubis (g) \\
\hline$A=0$ Kontrol $(-)$ & $738,00 \mathrm{e}$ \\
$B=0$ Kontrol $(+)$ & $308,46 \mathrm{a}$ \\
$\mathrm{C}=10^{5}$ & $468,00 \mathrm{~b}$ \\
$\mathrm{D}=10^{6}$ & $499,96 \mathrm{bc}$ \\
$\mathrm{E}=10^{7}$ & $506,86 \mathrm{bc}$ \\
$\mathrm{F}=10^{8}$ & $551,73 \mathrm{~cd}$ \\
$\mathrm{G}=10^{9}$ & $603,63 \mathrm{~d}$ \\
$\mathrm{H}=10^{10}$ & $691,53 \mathrm{e}$ \\
\hline
\end{tabular}

Keterangan : Angka-angka pada lajur yang diikuti oleh huruf sama tidak berbeda nyata menurut Uji jarak Berganda Duncan pada taraf 5\% menghasilkan bobot segar kubis dengan rata-rata sebesar 691,53 $\mathrm{g}_{\text {tanaman }}^{-1}$, hasil ini mendekati hasil yang diperoleh pada kontrol negatif bobot segar kubis yang

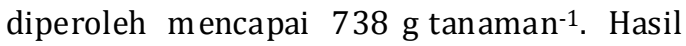
analisis pada tingkat kerapatan spora $10^{10}$ $\mathrm{ml}^{-1}$ spora dan kontrol positif berbeda nyata terhadap bobot kubis. Hal ini dikarenakan adanya pengaruh tingkat kerapatan spora yang mampu menekan perkembangan larva P. xylostella sehingga pertumbuhan tanaman khususnya dalam pembentukan krop kubis dapat terjaga. 
Berat segar krop kubis sangat berhubungan dengan besar kecilnya diameter krop pertanaman. Berdasarkan penelitian, tingkat intensitas serangan berpengaruh terhadap besar kecilnya diameter krop dan bobot segar yang dihasilkan. Krop kubis merupakan tempat penimbunan fotosintat sebagai hasil dari proses fotosintesis, besarnya fotosintat yang terkandung akan menyebabkan krop semakin padat dan besar sehingga akan berpengaruh terhadap berat segar krop. dimana perlakuan kontrol maupun tingkat kerapatan spora tidak terlalu menurunkan produksi kubis.

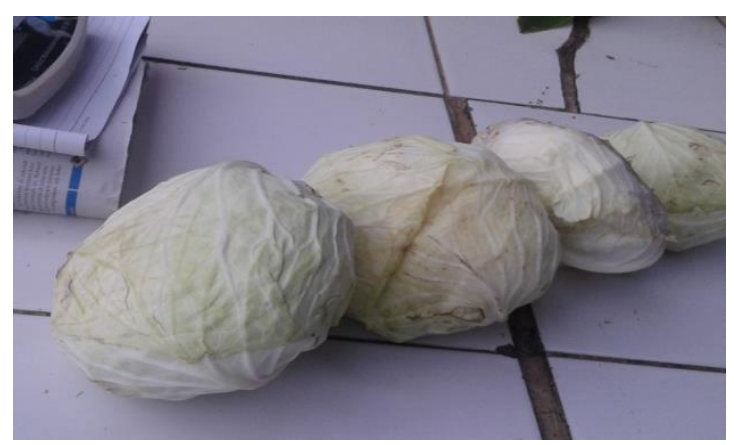

Gambar 2 Bobot Segar

Karena intensitas serangan termasuk ke dalam intensitas ringan, intensitas serangan larva hanya 3,12 sampai 13,68\%. Hal ini dapat dikatakan bahwa intensitas serangan larva P. xylostella dalam penelitian belum mampu menurunkan produksi kubis dimana intensitas serangan termasuk ke dalam kategori ringan yaitu (< $58 \%$ ), dan berada di bawah ambang pengendalian dengan kata lain tingkat mortalitas yang tinggi dapat menekan intensitas kerusakan pada tanaman. Keberadaan organisme pengganggu $P$. xylostella tidak akan mengakibatkan kerugian yang berarti dengan cara mempertahankan serangannya pada tingkat yang rendah atau tidak terjadi kerusakan. Semakin rendah intensitas serangan hama maka pertumbuhan diameter krop dan hasil tanaman kubis dapat dipertahankan.

\section{SIMPULAN}

Persentase intensitas serangan terendah pada penelitian ini terdapat pada tingkat kerapatan $10^{10} \mathrm{ml}^{-1}$ spora dengan intensitas kerusakan tanaman sebesar 3,12\% dan dapat menekan intensitas kerusakan serta mempertahankan serangan pada tingkat yang rendah. Semakin rendah intensitas seranga $P$. xylostella maka pertumbuhan diameter krop dan hasil tanaman kubis dapat dipertahankan dimana hasil bobot kubis pada tingkat kerapatan $10^{10} \mathrm{ml}^{-1}$ spora mencapai 691,53 g tanaman $^{-1}$.

\section{DAFTAR PUSTAKA}

Balai Besar Perbenihan \& Proteksi Tanaman Perkebunan Surabaya. 1997. Modul Quality Control (QC) APH Golongan Cendawan. Tim QC APH.

Deptan. 2008. Pengendalian Hama Tanaman. Agribisnis. Jakarta : Departemen Pertanian.

Harjadi S,S. 1986. Pengantar Agronomi. Gramedia. Jakarta.

Kalshoven, L.G.E. 1981. Pests of Crops in Indonesia. Van der Laan PA, penerjemah. (Terjemahan dari: De Plagen van de Cultuurgewassen in Indonesie). Jakarta: Ichtiar Baru-Van Hoeve.

Kementrian Pertanian. 2016. Informasi data sub sektor hortikultura : Jakarta. 
Norman, D.J., Henny, R.J. \& Yuen, J.M.F.. 1997. Disesase resistence in twenty dieffen bachia cultivars. Hot science. 32 (4): 709-710.

Sitompul, S.M \& Guritno, B. 1995 Analisis Pertumbuhan Tanaman. Yogyakarta: Gadjah Mada University Press

Tanada. Y., \& Kaya, H.K. 1993. Insect Pathology. Academic Press.inc. California.

Tkaczuk, C., Król, A., Safaryanand, A.M \& Nicewicz, L. 2014. The occurrence of entomopathogenic fungi in soils from field cultivated in a conventional and organic system. Journal of Ecological Engineering, Vol.15, No. 4. pp.137- 44.

Toffa, M.J., Atachi, P., Douro, O.K. \& Tamo, M. 2014. Pathogenicity entomopathogenic fungi

Metarhizium anisopliae and Beauveria bassiana on larvae of the legume pod borer Maruca vitrata (Lepidoptera: Crambidae). J. Agric. Biological Sci. 9: 55-64.

Trizelia, M., Syahrawati \& Mardiah, A. 2011. Patogenitas Beberapa Isolat Cendawan Entomopatogen Metarhizium Spp. Terhadap Telur Spodoptera litura Fabricius (Lepidoptera: Noctuidae). Indon. J. Entomol. 8 (1): 45-54.

Widiyanti., Ni Luh, P.M \& Muyadihardja, S. 2004. Uji toksisitas Cendawan Metarhizium anisopliae terhadap larva nyamuk Aedes aegypti. Media Litbang Kesehatan $14: 3$. 